Article

\title{
Governing Sustainability: A Discourse-Institutional Approach
}

\section{Audley Genus}

Kingston Business School, Kingston University, Kingston Hill, Kingston upon Thames, KT2 7LB, UK; E-Mail: a.genus@kingston.ac.uk; Tel.: +44-208-417-5665.

Received: 23 October 2013; in revised form: 21 November 2013 / Accepted: 6 December 2013 / Published: 6 January 2014

\begin{abstract}
The paper considers problems and possibilities connected with governing and realising the "transition to sustainability" - or at least to a more deeply resilient energy system. Conceptually its focus is on neo-institutional analysis and critical discourse analysis and the development of a discourse-institutional perspective. The first strand of the paper outlines the limitations of and potential insights into the governance of sustainability transitions that may be derived from adopting an approach based on a more thoroughgoing appreciation and application of work in sociology on neo-institutional theory. The second strand of the paper concerns discourse, recognising the role of text, discursive practice and social structures in framing the possibilities considered available and legitimate for governance. The two strands are brought together in a discourse-institutionalist framework, an approach that is illustrated by a case study of microgeneration in the UK. The paper's conclusion makes suggestions regarding the conduct of future research employing the proposed approach, and for furthering our understanding of issues connected with the governance of sustainability transitions.
\end{abstract}

Keywords: institutional theory; sustainable communities; critical discourse analysis; transition to sustainability

\section{Introduction}

In the UK and elsewhere there has been much discussion about how to meet challenging commitments relating to the possible harm and costs connected with anthropogenic climate change and the emission of greenhouse gases. The debates bring to the fore questions regarding the effective governance of the "transition to sustainability". Here, governance means the shaping of society in desired directions [1] or, more fully, "systems of rule (meaning "control" or "steering") at all levels of 
human activity, aimed at modifying behaviour and involving principles, norms and decision-making procedures" [2]. Governance has been thought of as a matter of economics, in which the coordinating role of markets is primary, politics in which the "steering" is accomplished by government and other actors, or sociology, in which shared norms, behaviour and identities are brought into focus. It should also be conceived of in relation to discourse, in which the role of language and meaning play an important role.

Across disciplines, institutional perspectives of sustainability have emerged. Relatedly, Arthur Mol contemplates changes required of "modern institutions" in order to "overcome the environmental crisis" [3]. The institutions he refers to include economic ones, such as commodity and labour markets, and "regulating" ones such as science and technology organisations and the state. On the latter, Mol is concerned with the anxiety and doubt which are hallmarks of "reflexive modernisation" in which occurs the parallel transformation and undermining of such institutions. It is argued here that previous work is either under-theorised or undervalues the potential insights into such developments to be derived from neo-institutional theory, as originally developed within sociology and organisation studies.

There has been much discussion of the role of institutions in economic development and performance. However there has been a marked lack of agreement on what "institutions" are. For example, scholars in the neo-classical tradition are concerned with "competitive markets" as focal institutions in which actors who are remote from each other buy and sell, and in doing so maximise utilities and profits [4]. In contrast, institutional economists attempting to loosen the rationalistic assumptions attributed to "homo economicus", while incorporating more realistic behavioural precepts into an evolutionary perspective, draw attention to inter alia: the formal, purposive structures and the informal constraints which shape behaviour [5-7]. Despite differences in the breadth with which the term is applied, institutions are generally understood as "the rules of the game" and actions (or the "humanly devised constraints that shape human interaction") that "reduce uncertainty by providing structure to everyday life" [6].

One of the interesting insights to be gained from texts in economics which deal with institutions and/or innovation concerns the appeals made to phenomena which are in part sociological and psychological, as well as economic. For example Veblen - a key figure in the founding of an institutional perspective in economics - considers how "settled habits of thought" underpin behaviour [4]. North, in his discussion of informal constraints, asserts that their origins lie in "socially transmitted information" and that they are part of the "heritage that we call culture". He quotes Johansson is describing culture as a "language based conceptual framework" that can "code" for "perceptual, attitudinal, and moral (behavioural) as well as factual information" [6]. Edquist and Johnson note that institutional economists have adopted a sociological conception of institutions as factors which "pattern behaviour, e.g., routines, norms, shared expectations, morals" but have rarely employed it to address innovation [4]. Coming up to date, the period since the year 2000 has seen researchers of innovation and transitions attempt to bring sociological institutions into analyses of socio-technical transition, albeit incompletely.

The paper considers what has been learned from this work about the role of sociologically understood institutions in effecting innovation which may contribute to a wider transition to sustainability, and its relevance to improving the governance of transformative change. Of particular interest are the concept of institution employed and the manner in which analysis of institutions has 
been carried out. The paper argues that greater depth and sophistication is required to apply more fully a neo-institutional approach to institutional analysis in order to realise the potential insights that this perspective offers to the issues of concern here. Further, the paper argues that there is an opportunity to deepen our understanding of institutional creation, persistence and change present in the development and adoption of a discursive view of institutions, an approach which has begun to take shape in the disciplines of geography and environment policy but to a lesser extent in literature on innovation and systems transitions. Thus the paper is informed by work on critical discourse analysis, which provides methods for conducting social research based on the analysis of language. In relation to the concerns of this paper, applying CDA affords an opportunity to open up the governance of sustainable transitions to expose sources of influence, persuasion and dominance implicated in the making of or adherence to institutional rules. The political programme of CDA brings into focus those individuals, groups or organisations excluded or marginalised from - in this case - sustainability governance. As a leading proponent of CDA states: "it often makes sense to use discourse analysis in conjunction with other forms of analysis, for instance ethnography or forms of institutional analysis", to address the "socially constructive effects of discourse" in terms of the generation and maintenance of institutions connected with the governance of environmental sustainability [8].

The paper proceeds as follows. Section 2 outlines the neo-institutional approach, marking up its relevance to the study of sustainable transition while reviewing previous relevant research. Section 3 argues the case for applying critical discourse analysis to the study of the governance of environmental sustainability. Section 4 proposes a discourse-institutional approach to understanding the governance of sustainability transitions, which is illustrated in Section 5 by reference to a case study of the institutionalisation of microgeneration in the UK. Finally, Section 6 presents the conclusions of the paper, in which the work of the paper is summarised and some suggestions about future research are made.

\section{An Emerging Perspective: Neo-Institutional Theory and the Governance of Sustainability}

There are various approaches to neo-institutional theory to be found within sociology and organisation studies $[9,10]$. Variations on the theme have been applied to the study of organisations, especially in case studies of public sector and voluntary organisations, of how the "infusion of value" enables them to endure [11]. Other variants have conceived of institutionalisation as a process within and a property of organisations, and have been concerned with the "what" and the "how" of social order, for example to address how the settled "legitimacy" of a new practice induces later adopters to adopt it, whereas early adopters introduce it for competitive reasons [12]. Another version of neo-institutional analysis has addressed a fuller range of actors and sources of isomorphic institutional change [13], including cultural and symbolic factors [14] and recognising multiple rather than monolithic institutional environments. Such work presaged the need to unpack "social structures" (such as class, the economy, the family, the church) which in previous incarnations of neo-institutionalism required an adaptive response on the part of organisations or other social entity. Moreover, an opportunity was presented to extend the scope of and change the focus of institutional analysis in favour of "bringing society back in" [15]. 
The paper builds on these developments to argue for an institutional dimension to the governance of the transition to sustainability. It draws on the work of contributors such as Jepperson [16] and Scott, who defines "institutions" as:

"social structures that have attained a high degree of resilience [and are] composed of cultural-cognitive, normative and regulative elements that, together with associated activities and resources, provide stability and meaning to social life" [9].

Scott identifies three "pillars" of institutions, four "carriers" of institutions, and mechanisms and processes by which institutions persist or change [9]. The three pillars of institutions are: (a) regulative; (b) normative; and (c) cultural-cognitive rules. Regulative rules are formal and relate to state legislation, policies, taxation provisions, subsidies, and technical and safety standards, for example. Normative rules confer role expectations and obligations on the actors and may be exemplified by professional codes of conduct. Finally, cultural-cognitive rules frame sense-making and are implicated in the symbolism attributed to objects and actions, including beliefs about technologies and conventional wisdom regarding the effectiveness or meaning of government policies. Institutional rules are transmitted by different types of carriers. Four types of carriers have been identified: (a) symbolic systems including rules, laws, values, expectations, categories, typifications and schema; (b) relational systems including governance systems, power systems, regimes, authority systems, structural isomorphism and identities; (c) routines including protocols, standard operating procedures, jobs, roles, obedience to duty and scripts; and (d) artefacts including objects complying with mandated specifications, objects meeting conventions and standards, and objects possessing symbolic value [9,16,17]. One may also identify three processes of institutionalisation: habitualisation; objectification; and sedimentation; and three mechanisms by which institutionalisation occurs: coercion, normative commitment and imitation [9]. Habitualisation refers to the process, pre-institutionalisation, by which new ideas and practices assume a taken for granted quality in the thoughts and actions of actors in a limited domain and begin to be recognised as such by others outside it. Objectification concerns the process by which the nascent institutional rules are articulated; it is the means by which institutions begin to solidify, a development that is necessary for sedimentation to occur. Sedimentation is the process through which rules seep into, first, an "organisational field", then possibly through wider society, and is a matter of deep and extensive diffusion. An organisational field is an empirically determined and "recognisable area" of social life, incorporating an aggregation of interacting firms, consumers, citizens, governmental agencies and other stakeholders necessary for its continued conduct but who, geographically speaking, may operate at a distance from one another [13].

Within studies of systems and sectoral innovation and technological and sustainability-related transitions, neo-institutional theory has been invoked to analyse the "deep structure" of socio-technical systems [18]. Here, there is argued to be a set of regimes, which comprise socio-technical systems; the stability of the regimes and ultimately of the focal socio-technical system relies in part on the rules which regime members have in common and which connect regimes with each other. Neo-institutional theory has been applied to analyse the diffusion (or rather lack of diffusion) of microgeneration technologies in the UK [19] and to examine social acceptance of smart electricity grids for distributed electricity generation [20]. Fundamentally, a shortcoming of this previous work is that "institution" has been used merely as a synonym for "non-market organisations" [18], "organisation", or governmental 
arrangements [21,22], without theoretical underpinning [23,24]. It has been criticised for being employed as a "left-over" category in analyses [18]. Prior research confirmed that firms' strategic behaviour is guided by prevailing principles and a concern for current markets served, shaped in relations with various societal actors $[25,26]$. More recent work, by Dolata, for example, describes institutional mechanisms contributing to inertia or allowing for technological and sectoral change, based on analysis of a number of sectors, such as the computer, pharmaceuticals and automobile industries [27]. There are mentions of standards and financing and technology transfer between various actors, and so on. But there is no specific or systematic identification of institutional rules, nor the ways in which firms are bound to prevailing institutionalised practices to diagnose the mechanisms which effect continuing compliance. Further, in following Streeck and Thelen there is a neglect of cognitive/cultural underpinnings of institutions, in which symbolic meanings - for example in relation to the credibility of government policy, or attached to particular artefacts - may become the subject of conflicting interpretations in times of crisis [28]. Taking this seriously renders the extent to which meanings and beliefs are shared or become divergent a proper object of study for neo-institutionalists. Geels has brought a sociological and neo-institutional perspective to bear on his work on socio-technical systems innovation, addressing the role therein of regulative, normative and cultural-cognitive rules and how their structuring of and shaping by interacting protagonists in distinct yet overlapping regimes [18]. However, this neglects consideration of certain important elements of the neo-institutional approach, such as the ways in which prevailing and novel practices and beliefs are carried and achieve sedimentation (or not). This is perhaps due to the masking of local phenomena that may be relevant to processes of habitualisation, objectification and sedimentation of institutions within relatively short, condensed case studies designed to examine innovations over long periods of time and involving a wide range of actors and events [29,30]. This tends to render aspects of the innovation/transition process "invisible", particularly non-governmental or informal processes. So, for example, in the case of the Dutch "energy transition" the question remains of how to account for fluctuations in the image of wind power in Dutch society between the 1960s and 1990s [29]. In the case of the transition from cesspools to sewer systems in Netherlands there is a similar glossing of how innovations in the sector spread in the period 1870-1930 [30]. Other related work has emphasised the work of diverse actors, networks and institutions, observing that firms "compete over the institutional set-up" [31,32] but has not explained the manner in which new ideas, practice and technologies spread across actors (institutional processes). Another study does make the basic distinction between "hard" and "soft" institutions [33] and tries to understand how both types affect institutional entrepreneurship for sustainable urban development. Whereas they do not explain mechanisms of compliance with existing rules Woolthuis et al. do show how entrepreneurs engage in processes of "theorization", for example, to elicit legitimacy for new approaches to contracting, for instance, which challenge current institutions. Bearing in mind the approach adopted here it is interesting that Woolthuis et al. recognise a role for language (or at least narrative) in their analysis of the tactics of institutional entrepreneurs and employ a combination of approaches and data sources to enhance the validity of their research [33].

In focusing on innovation systems extant research has tended to overplay production at the expense of consumption whilst neglecting to situate phenomena adequately in their social, political, historical and institutional context. Thus, factors (and indeed actors) fundamental to the configuration and reworking of institutions related to socio-technical systems are likely to be missed. As well as more 
completely drawing on neo-institutional theory the paper draws on a critical approach to discourse analysis in order to avoid the pitfalls identified above. A summary of research employing discourse analysis to obtain insights into the substantive issues of concern to the paper is presented in the following section, after which a proposed discourse-institutional approach is outlined.

\section{Discourse Analysis of Environmental Sustainability}

Connected with the governance of sustainability transitions there have been notable contributions to our understanding of urban sustainability discourses [34] and the politics of environmental discourse [35]. Mazza and Rydin point to three constraints on the integration of environmental sustainability concerns into urban planning policy: (a) the dominant role of economic interests in shaping policy discussions; (b) the degree to which the admission of environmental issues into policy discussions relies upon the involvement of environmental groups and their representatives; and (c) the (un)availability of local tools and resources that limit discussion of sustainability themes. They base their analysis on identification of actors and their roles in urban policy-making in designated research sites, the assessment of local networks of significance to policy-making and a definition of multiple, possibly overlapping policy-making discourses. The latter they refer to as "images" of urban sustainability [34].

Hajer combines analysis of discourse through which reality is produced with analysis of social practices from which constructs emerge and in which actors who make statements engage [36]. At the heart of his work are discourse coalitions, which are groups of actors sharing a social construct in relation to environmental debates and policy-making. Hajer marks up the role of storylines in (more or less) synthesising different discourses into a (somewhat) coherent whole, whilst masking the complexity of discourse. For Hajer, domination and institutionalisation of discursive space produce "solidified" social practices and reasoning. In this way, practice is the medium by which certain actors impose their views of sustainability on others. Fischer considers how the over-reliance on experts and a technical framing of policy issues contribute to weakening the influence of citizens over environmental politics in the USA, a phenomenon which is accomplished by the growth of powerful economic and governmental institutions (used to mean "organisations") [37].

Smith and Kern analyse storylines in Dutch environmental policy-making, concerned that co-option of environmental storylines into incumbent interests and prevailing discourses impacts negatively on the subsequent institutionalisation of ideas and thinking about environmental sustainability [38]. Smith and Kern give an account of the successful diffusion of the "flexible storyline" of Dutch environmental transition, which owes much to collaboration among researchers of sustainable transitions and policy makers in The Netherlands. The openness to reinterpretation of this storyline enabled a range of governmental actors to "buy into" the developing environmental policy. However, this came at a price, since the coalition had to develop an approach which could "work with the grain" of the commitments of other government ministries (other, that is, than the Ministry of Housing, Spatial Planning and Environment, which was the government department responsible for developing the new policy). Hence the transition approach in Netherlands, fearful of remaining a "sideshow", incorporated "market-based instruments", the new commitment to liberalise the Dutch energy market and a concern to develop the "knowledge economy" [38]. 
Rydin [39] draws upon the work of March and Olsen [40] and Elinor Ostrom [41] in attempting fill the gap in institutional analysis of environmental planning with fuller attention to "language use in communicative situations". March and Olsen had pointed to but did not analyse the importance of language in institutions. Ostrom's IAD (institutional analysis and development) framework made it clear that all (institutional) rules-defined as "shared understandings" regarding what actions are "desirable, prohibited or permitted"-are formulated in language. However Rydin sees this as insufficiently addressing the role of language, a shortcoming she argues may be remedied by bringing in a discursive element to the analysis. Thus she develops an institutionalist framework in which regularities in language use, actors' discursive strategies, linguistic resources and interactions in communication, analysed using a rhetorical method, take centre stage.

As with the work discussed in the previous section, much research on discourses of environmental sustainability addresses institutions as organisations, particularly focusing on governmental organisations, and what contributors variously refer to as the "institutional set up" or "institutional context". Specifically, Hajer is concerned with the implications of discourse analysis for the creation of institutional practices, which afford more democratic debates about environmental issues [36]. Rydin considers the potential of "new" environmental policy-making institutions such as citizen juries or group evaluation exercises in bringing together "polyphonic" communities whom formal authorities must learn to trust [42]. Smith and Kern consider the implications for more radical transition "storylines" of the capture of environmental discourse by mainstream interests (or "institutional priorities") [38]. In addition to seeing "institution" as ministerial priorities, Smith and Kern depict as institutional innovations the transition platforms, themes, pathways and experiments created by the Dutch economics ministry as the embodiment in practice of the new energy transition policy. Rydin's approach to discourse and institutions makes a valuable contribution to understanding the significance of language in social organisation but omits to attend fully to social context (and the role in its creation played by discourse) as political phenomena [39]. In a sense this is a criticism of the linguistic school of discourse analysis, which may be contrasted with the programme of critical discourse analysis, in which the actual language use within social and political processes (e.g., of governance) that render certain actors marginal is of central interest. Further, a critical approach to discourse analysis, in addressing what it is about political systems (such as "new capitalism") that constrains or facilitates our ability to develop our potential as members of society, attends to a social, rather than an individualised notion of speech and acting. It also spurns positivist methodology in favour of a more honest recognition and reflection on values, including those of analysts. In addition, such approaches fail to unpack the nature of institutions and processes of institutional change in a way that would shed light on the character of these phenomena.

These contributions are insightful in the ways discussed above. Yet, appreciative insights could be obtained regarding a discourse-institutional perspective if the conceptual underpinnings of such an approach were more fully articulated. This applies to the definition of the types of institutions that may be of significance to governance and innovation linked to the transition to sustainability. It applies also to the carriers, mechanisms and processes by which institutionalisation, non-institutionalisation or deinstitutionalisation of regulative arrangements, norms and cultures occur. None of the foregoing are explicated in previous work as they might be were an appeal to neo-institutional theory be made. Furthermore, such institutional analysis could be strengthened by addressing in a more rounded way 
the role of discourse in substantiating the institutions and institutional processes identified. This would necessitate an approach transcending discourse as merely linguistics or purposive use of language. In this regard what earlier contributions have lacked is a comprehensive analysis of text, discursive practice and the social conditions governing these, which together with non-discursive material elements (re)produce the institutional reality of governance in relation to the transition to sustainability. This criticism applies to previous discourse-institutionalist work on environmental sustainability $[39,41,43]$.

\section{A Discourse-Institutional Approach to the Governance of Sustainability}

This section sets out an approach to the governance of environmental sustainability, which brings together thinking about critical discourse analysis and neo-institutional theory. At its core, the approach is concerned to enable analysis of ways in which society enlarges or reduces possibilities for various actors to frame and address the salient problems that affect its development. The approach is thus concerned with the role of discourse in differences (or more strongly "struggles") about such framing, and the actions that are suggested or taken to remediate problems or to pursue opportunities. The approach draws on critical discourse analysis (CDA) to address the infusion of language (as text, discursive practice and social practice) with "both the immediate conditions of the situational context and the more remote conditions of institutional and social structures" [44]. With regard to the latter there is much to be gained from adopting a neo-institutional perspective in combination with CDA. In this respect, the approach of the paper addresses the (apparent) permanence of certain organisations, norms and attitudes but also recognises the possibility of institutional entrepreneurship which affords, but does not necessarily secure, opportunities for social and political change, including that which is of relevance to the governance of environmental matters. However, while Fairclough refers to the remoteness of institutional "conditions", it would be a mistake to ignore the rule-like nature of institutions and processes of institutionalisation, which are created, reproduced and manifest in everyday interaction and text. Whilst CDA is connected with the stabilising effect of power which (re)produces what Fairclough calls "conventions", neo-institutionalists such as Scott refer to "rules" and other aspects of institutions that are embedded in and with practice, through a variety of mechanisms [8,9]. A discourse-institutional approach can in a complementary way account for discursive and non-discursive aspects of conventions/rules by investigating: (a) the language aspect of the phenomena under scrutiny; and also (b) the non-discursive elements of social structure that both Fairclough and Scott consider to have a shaping effect on individual and collective behaviour and to be constituted thereby.

Figure 1 shows a framework for understanding the governance of environmental sustainability, which illustrates the proposed discourse-institutional approach. The various elements of the diagram and how they relate to each other in a discourse-institutional perspective need to be explained. The governance of environmental sustainability is depicted as regularities in text and discursive practice; these have a dialectical relationship with social practice, the prevailing historical context and social structures (or overarching rules of the game) which shape and which are partly shaped by those discursive regularities. Thus new institutional rules are created in speech and writing and visual "events" (text), and in discursive practice as well as by non-discursive phenomena. They may (or may not) be institutionalised depending on the strength and effectiveness of the coercive, obligatory and 
mimetic mechanisms underpinning the three types of institutional rules in question, and the carriers via which they are transmitted. Table 1, below, shows which mechanism underlies each of the three kinds of institutional rule. The extent to which these new rules are pervasive is a matter of their sedimentation, connected with processes of diffusion and their legitimacy. Such diffusion may be partial and limited to "habitualisation" or "objectification" at a level below that of the organisational field or wider society. Institutionalisation may fail (non-institutionalisation) and prevailing rules may be reinforced (reinstitutionalisation) or undone (deinstitutionalisation).

Figure 1. A discourse-institutional perspective of the governance of sustainability transitions.

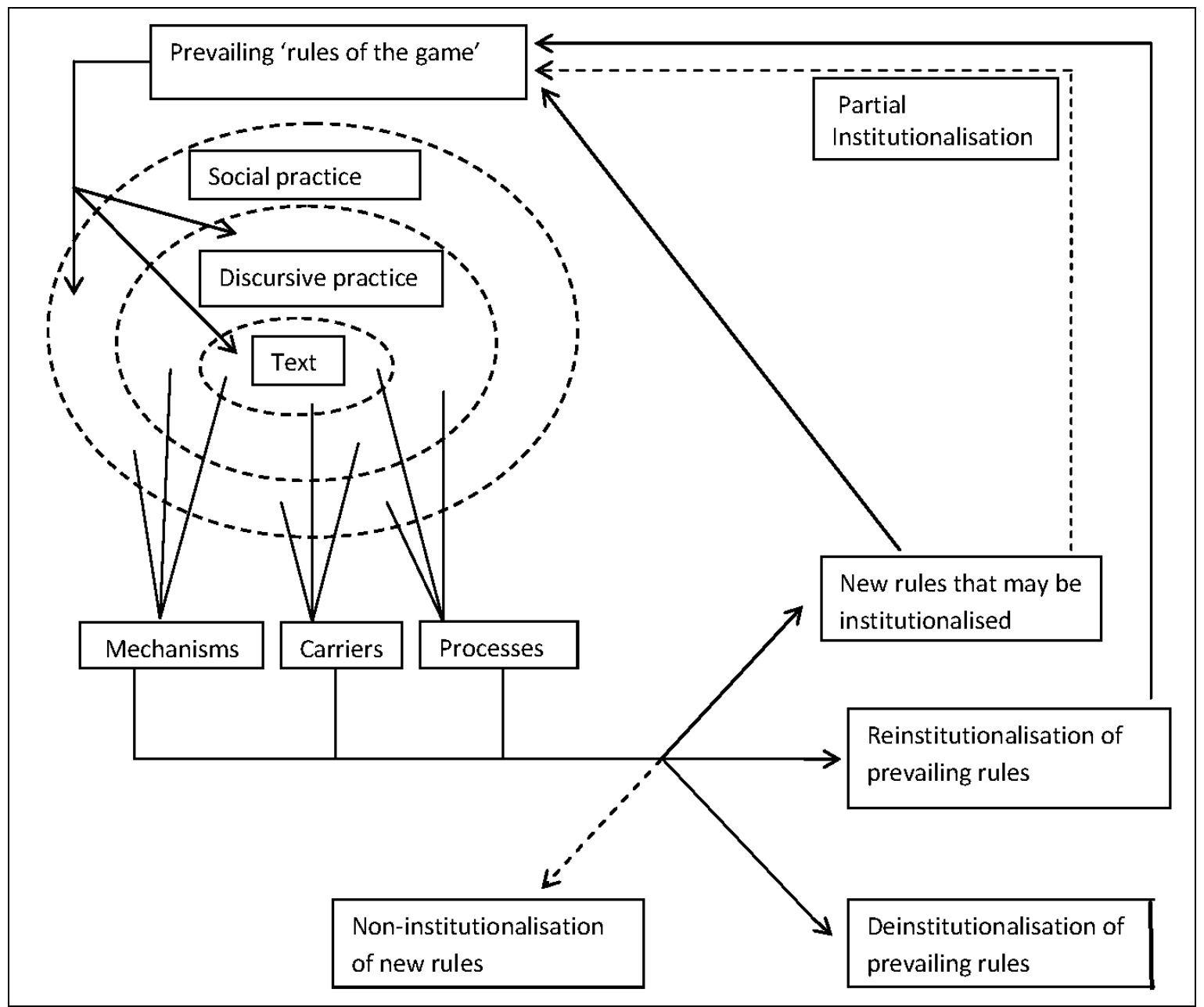

Table 1. Institutional mechanisms underpinning institutional rules.

\begin{tabular}{cc}
\hline Institutional Rule & Institutional Mechanism \\
\hline Regulative & Coercion \\
Normative & Obligation; proper conduct \\
Cultural-cognitive & Imitation; shared assumption \\
\hline
\end{tabular}

The notion of rules of governance as text points to manifestations of language to be found, for example, in written policy documents, laws, business strategies, or reports by NGOs in the discursive domains connected with environmental sustainability. They are implicated therefore in regulative, normative and cultural and cognitive rules of sustainability. The text(s) define the "how", the "why" 
and the "what" of environmental sustainability as constituted in the language and legitimation strategies that various protagonists employ, and the "who" (e.g., in terms of whose voices and actions are required, absent or muted). Quoting Berger and Luckmann, Fairclough argues that "legitimation provides the "explanations" and justifications of the salient elements of the institutional tradition". Thus "[p]eople are constantly concerned in social life, and in what they say or write, with claiming or questioning the legitimacy" of policies, viewpoints and actions [8]. This means that textual analysis is an important resource for researching legitimation and institutions. As Fairclough states, texts are the "products" or "events" of language use and critical discourse analysis aims to analyse various dimensions of that language use (see Table 2, below) [8]. The stabilisation, diffusion and transmission of new rules are affected by prevailing social structures and historical context that have discursive and non-discursive "moments" or dimensions. Both discursive and non-discursive dimensions require analysis. Such analysis will take the form of discursive analysis of texts and neo-institutional analysis, for which documentary, interview or other data will be required.

Table 2. Dimensions of critical discourse analysis.

\begin{tabular}{ll}
\hline Dimension & Object of Analysis \\
\hline Text & Legitimation strategies and intertextuality \\
Discursive practice & Discursive domains; genres; styles; representations; discourse coalitions/clusters \\
Social practice & Social structures and historical context of discourses and text \\
\hline
\end{tabular}

Texts are not straightforwardly the "products" of social structures such as language or class or economic and political systems. Rather, social structures provide "a range of possibilities" and "members resources" which protagonists bring to the interpretation and production of discourse and other elements of discursive practices, including "genres" and "styles". A "genre" is a way of acting in social life, examples including interviews, speeches or meetings, whereas the term "style" refers to ways of being, which connote the identities of protagonists and those they apply to others. Both of these may be distinguished from "representation", which refers to different perspectives applied to the comprehension of reality. Discourses do not stand alone but may be interconnected. Hence one speaks of intertextuality or interdiscursivity - which are phenomena through which one text or discourse draws upon, combines or influences others.

Discourse analysis and neo-institutional analysis both draw on and will likely benefit from inter- or trans-disciplinary approaches to research, which will entail different choices regarding the kinds of data and analysis to be selected and the concepts to be applied $[9,45]$. Neo-institutional analysis may emphasise regulatory, normative or cultural aspects, or attempt to address all three; critical discourse analysis may entail the examination of linguistics or semiotics to a greater or lesser degree, within its study of language, social interaction and power relations. Accordingly, the framework is not offered as a universalist approach applicable across the full range of contexts to be investigated or compared but as a more disciplined investigative point of departure for examining phenomena and questions in particular cases, which brings together discursive and non-discursive perspectives to shed light on issues of power, social relations and institutionalisation. The following section illustrates how the framework might be applied to the analysis of the governance of environmental sustainability in the UK. The illustration takes the form of a case study of the institutionalisation of small-scale energy 
generation (or microgeneration) in the UK, the institutions and discourses connected with this and the implications thereof for governance and sector growth.

\section{Applying the Framework: Microgeneration in the UK}

Some of the main issues to be confronted in applying a discourse-institutional framework are discussed below as the illustrative case is presented. Firstly, the choice of research object should be a problem for society, which may be identified by groups or individuals in society, or by the researcher(s), to which the research can contribution insight or possible solutions. Here, the choice of the governance of sustainability in the UK, and within that the focus on microgeneration, are justified as research objects by dint of their salience to the problem of mitigating and adapting to climate change, and because they offer an opportunity for theoretical development. Here, there is the potential to build a language aspect of neo-institutional theory to deepen understanding of the promotion and limited success of microgeneration in the UK. The research question connected with this choice of research problem is the following: What discursive and institutional factors explain the uneven uptake of microgeneration technologies in the UK over the last ten years (i.e., since 2003)? In answering this question, a neo-institutional analysis may be conducted to examine the boundaries of the organisational field and constituent institutional rules, mechanisms, carriers and processes. The organisational field comprises the array of interacting actors who create, rewrite or contest the "rules of the game" of microgeneration. In the UK, these include the New Labour and Coalition governments, particularly the Department of Energy and Climate Change (since its creation in 2008), Department for Communities and Local Government, the Department of Trade and Industry and its successors DBERR, DIUS, and BIS, and the Treasury; incumbent and new entrant energy firms, NGOs (such as Friends of the Earth and Greenpeace); industry associations such as the Renewable Energy Association and Micropower Council; installers of microgeneration systems; the Building Research Establishment; inspectors who monitor standards in relation to accreditation and certification of installers and suppliers; and householders, communities and business who apply for grants and/or who install small scale energy generation systems.

The collection of data in the proposed approach relies, from a discourse analytic perspective, on a selection of "typical" and "important" texts, the choice of which is governed by the research question and methodology, their availability and the prevalence of project resources — not least time - to effect data collection and analysis. These may be "naturally occurring" texts such as government, newspaper or company reports, articles or speeches by protagonists. Important texts in the present case are: the UK Low Carbon Transition Plan, (2009); A Framework for Pro-environmental Behaviours (2008); the UK Renewable Energy Strategy (2009); the UK Microgeneration Strategy documents of 2006 and 2011; and the Public Consultation on a Microgeneration Strategy document (2010) [46-51]. Text from transcribed research interviews may also be used, though researchers need to be mindful of any researcher bias brought into the conduct and interpretation of interviews and interview content (as with any research). In this case, data from a study of microgeneration previously conducted by the author together with the aforementioned documents comprise a corpus of text, the former being drawn from interviews held in 2007/8 with industrialists, academic researchers, energy support advisers and policy-makers connected with microgeneration in the North East of England. Data from available 
public and semi-public archive and contemporaneous documents may provide supporting contextual data. In this case these are used to illustrate the policy and financial context of microgeneration in the UK in the period under review. The analysis of texts along with analysis of discursive practice and social structural factors (social practice) generates evidence of institutional rules promoting and inhibiting microgeneration and an explanation of the argumentation employed to justify or legitimise this and the social relations by which diffusion of microgeneration is accomplished. The neo-institutional analysis entails identification of regulative rules such as legislation, subsidy programmes, normative rules manifest in professional codes of conduct, certification and accreditation, and cultural-cognitive rules such as mental models and shared values. Such an account needs to address material resources at stake (e.g., funding allocations provided by state subsidies or fines imposed in cases of noncompliance with law) and the implications for action taken or not taken by those whose behaviour is constrained by the institutional arrangement in question.

\subsection{Institutions: Rules and Mechanisms, Carriers and Processes}

In relation to regulative institutional rules one can point to a number of laws and regulations, enacted by government, related to the promotion of microgeneration in the UK and which have a coercive or mandating effect. A short list includes the following: Climate Change Act 2008; Energy Act 2004 and 2008; Planning and Energy Act 2008, Sustainable Energy Act 2003; the Renewables Obligation; Code for Sustainable Homes; the Green Deal and Energy Company Obligation (2013); Energy Performance of Buildings Directive; various levies and taxation measures and numerous technical safety standards for electricity supply. In addition a number of strategies, policy documents and incentive programmes have been introduced. To name a few these include: the UK Microgeneration Strategy (2006); UK Microgeneration Strategy (2011); UK Low Carbon Transition Plan (2009); A Framework for Pro-environmental Behaviours (2008); The Renewable Heat Incentive (launched November 2011 for non-domestic generators); Feed-in Tariffs (launched in April 2010, enabling powers for both the RHI and FIT were set out in the Energy Act of 2008); Clear Skies; Climate Investment Fund; Clean Technology Fund; Low Carbon Buildings Programme (launched in 2006); and the legislative underpinning of the Microgeneration Certification Scheme (MCS). Specific elements of the MCS include provisions for standards for testing renewable energy technologies, some are similar across different technologies and/or have been the subject of international collaboration and agreement between nation states. For example, the standard IEC 61400-2 applies to the testing of microwind energy technology and has been adopted by several EU countries and also Canada and the USA.

In terms of normative rules, as well as the MCS, the documentary material quotes methodologies such as SAP, RDSAP, and BREDEM, which have been institutionalised through legitimation by the state for the assessment of the energy performance of buildings. Normative institutions also include normalised roles for participants, though requiring an expectation of activity rather than the "moral" basis of compliance typically associated with normative institutions in the literature on neo-institutional theory. New roles for incumbent energy firms and citizen/community generators - whereby the former act as service providers for the latter-were mentioned by interviewees as becoming more prevalent in the UK. This has not become a standard practice though and cannot be said to be deeply sedimented across the organisational field. Particular incumbent energy firms were cited as engaging in novel 
routines (a process of habitualisation therein), which requires change in the relationship between user and (former) energy provider in order to substantiate and "carry" the institutional change.

Cultural-cognitive rules cited by interviewees include: awareness and positive images of microgeneration created by climate champions, including exemplary local authority initiatives and the citizen science of "tinkers and fiddlers" related to community energy schemes. Interviewees referred to the symbolic power of artefacts such as wind turbines installed on property and how this could help to promote diffusion of small-scale energy generation (by carrying the institutional innovation) and, not least, the idea that citizens could actively participate in realising a sustainable society (which may entail their thinking differently about their identity as consumers or citizens).

The uptake of microgeneration in the UK has been patchy and partial. Why? Clearly, part of the answer lies in the weakness and weakening of rules supporting institutionalisation, including reduction of material support by the Coalition government, as it sought to reduce public spending during the recession which began in the aftermath of the financial crisis of 2007-2008. For example, the Low Carbon Buildings Programme (LCBP) was launched in May 2006, with a budget for three years of $£ 30$ million, which was described as "a pittance" [52]. A system of monthly rationing of grant allocations was imposed soon after its launch and these monthly allocations were very popular-with more than half of the grants awarded being for solar thermal installations - and exhausted well before each month's end (hours in the case of the February 2007 allocation), leading to the suspension of LCBP in March 2007. Its relaunch in May 2007 came with lower maxima for grants for the various technologies, and for the domestic funding stream a maximum grant per household of $£ 2,500$ that was viewed as forcing households to choose between rather than to combine renewable technologies to install. Household grants for all technologies supported by the scheme fell by two-thirds in the nine months following the relaunch of the scheme. [52]. Without advance notice it was announced that the LCBP was to close to applications involving electrical microgeneration on 24 May 2010, though it did not finally do so until the following year. There is now a hiatus between the closure of the LCBP and the launch of the domestic element of the Renewable Heat Incentive (delayed from 2011 until at least 2014), creating much uncertainty among potential adopters and suppliers. As for Feed-in Tariffs, the numbers of installations jumped from over 30,000 in 2010-2011 (year 1) to 247,000 in 2011-2012 (with installed capacity increasing from over $108 \mathrm{MW}$ to $982 \mathrm{MW}$ in the corresponding period and solar PV technology accounting for $92 \%$ of installed capacity) [53]. Feed-in Tariff scheme costs rose from about $£ 15$ million in 2010-2011 to over $£ 150$ million in 2011-2012. Concerns about overspending on the scheme (about $£ 1$ billion more than budgeted for in the Spending Review period) prompted DECC to introduce "degression" rules entailing the reduction of tariffs with increasing deployment of a technology [53]. Such withdrawal or reduction of state support acts symbolically as well as materially as a brake on institutionalisation (as a kind of negative institutional carrier of microgeneration). It is possible to shed further light on this by considering the contradictory tendencies affecting the "stop/go" nature of support for microgeneration in the UK and the role of language in legitimising them. 


\subsection{Text}

The extent to which government is credibly supportive and serious about microgeneration and small-scale community energy is expressed in the selected texts. For instance the DEFRA 2008 Pro-environment Behaviour document warns of the "challenging behaviour goal" represented by policy areas where "there is low ability and low willingness to act (e.g., install microgeneration)" [47]. An example of legitimation related to the absence of statutory targets for microgeneration is provided in an annex to the Renewable Energy Strategy 2009 document, which summarises responses made in an earlier public consultation on the subject. Thus it cites that there is "overall agreement with the Government's current position that it should not introduce statutory targets for microgeneration" [48]. This passage is taken as legitimising the position taken by the state, with authority being vested in the respondents who expressed such a view in the consultation. Rationalisation serves to reinforce the utility of prevailing centralised, large-scale electricity generation and expected problems of microgeneration. An example is a section of text within the UK Renewable Energy Strategy of 2009, specifically concerning renewables for centralised electricity, and states that:

"The Renewables Obligation, which requires electricity suppliers to source a specified and increasing proportion of their electricity from renewable sources, is our key current mechanism for incentivising renewable electricity. [We will] expand and extend our long-term incentive for major renewable electricity developments - the Renewables Obligation - to ensure that it can deliver around $30 \%$ renewable electricity by 2020 . This will provide continued support for largescale, centralised renewable electricity generation" [48].

According to the Microgeneration Strategy, 2011, a "suite of incentives and policy measures are supporting this transition to a low-carbon and less centralised energy economy". The Spending Review agreed over $£ 850$ million funding for the Renewable Heat Incentive which will be introduced in June next year. This will drive a more than tenfold increase of renewable heat over the coming decade, shifting renewable heat from a fringe industry firmly into the mainstream. Feed-In Tariffs will continue and will be refocused on the most cost-effective technologies saving $£ 40$ million in 2014-2015. All of this activity needs to be considered alongside the essential work to create certainty and security for large-scale electricity which remains the most important component of meeting our renewables and carbon targets at the national level" [50].

Text from the interview material reinforces the continuity of large-scale centralised electricity and idea that microgeneration is problematic. The following quotations are exemplary:

"It is the big companies like that, that are starting to get involved, that will help to turn the industry around. Otherwise, it is mostly mom and pop organisations." (Technical director, Renewable Energy Testing Company).

"Generally speaking reliability of supply is extremely high with the public network which everybody has access to. Smaller community schemes which may be wind, may be photovoltaic, may be biomass, generation schemes, are likely, almost certainly likely to be much less reliable so the electricity supply will not be there as often, the same number of hours in any average year for example. So you've got reliability and security of supply issues associated with small schemes. So, generally 
speaking, to ensure a reliable supply one needs the public supply which one could use as a back-up supply." (Senior manager, Energy Project Consultancy).

Legitimation also takes the form of narrative. One example from the interview material concerns the difficulties of installing a CHP unit at home, related to the author as follows:

"If you want to replace your boiler with a CHP unit, for example, if you take a hot water boiler and replace that with another hot water boiler, you need a plumber. You put a CHP unit in, you need an electrician as well. If it is connecting up to the meter, you don't only need an electrician, you need a meter-qualified person and...that's a guild of its own, is that" (Technical director, Renewable Energy Testing Company).

\section{Intertextuality}

The analysis of intertextuality refers to the presence of text within other text, and to the approach taken in a text towards recognising, contending with or accommodating difference. Intertextuality analysis demonstrates the effect on institutionalisation of the suppression or accommodation of different positions or perspectives, which allow a settling or disturbance of worldviews. The presence of texts within others is exemplified in the case of the Renewable Energy Strategy by reference to the renewable energy consultation, reports on the UK's wind resources, the Stern review on climate change, and on the renewables obligation. The text of the Microgeneration Strategy of 2011 refers to the Energy Act 2004, the Microgeneration Strategy of 2006, Green Energy Act 2009, the 2050 Pathways Analysis and the Consultation on Microgeneration of 2010, among others. Interdiscursivity is a kind of intertextuality, which in this case shows how the selected renewable energy and microgeneration policy texts typically refer to other discourses. A typical example is the Renewable Energy Strategy of 2009, which refers to the discourses of green economic growth, employment, energy security and independence, and industry development. There is a reference to the discourse of marketing in the usage of the term "clean cash back" to describe incentive payments to be made under the Feed-in Tariffs and Renewable Heat Incentive schemes. A particularly resonant formulation of language is the repeated reference to "keeping our electricity [or energy] supplies safe and secure" in the 2009 Low Carbon Transition Plan [46].

Policy documents identify microgeneration and community scale energy as a "sector" in which the "onus is on the industry itself" to take advantage of the opportunities presented by the financial incentives to identify and to address "barriers to sector growth" (this is cited in bold text on p. 4 of the Microgeneration Strategy 2011) [50]. The clear message is that the primary responsibility for this does not lie with the state. Moreover, these statements do not give the impression that citizens have much of a role to play. There is however reference to the role of "consumers" being to "continue to work" with industry and government to identify non-financial barriers to microgeneration but also to the work of a microgeneration Government Industry Contact Group which does not include consumers/citizens. With regard to the latter the 2011 Microgeneration Strategy accommodates difference in making reference to "our shared objective" being to move the microgeneration sector "into the energy mainstream, offering consumers affordable, and cost-effective low carbon energy products" [50]. It is interesting to note the reference at the end of the quotation to consumption of low cost products, and to "low carbon" as distinct from "sustainable" or "renewable". Moreover, in the text that follows the 
quoted passage, the Microgeneration Strategy refers to consumers being able to play 'their own part' in tackling climate change, which is seen as additional to the objective of the strategy of "delivering economic benefits".

\subsection{Discursive Practice}

In relation to discursive practice, which mediates broader social structures and more specific textual products, a discursive-institutionalist analysis of the selected texts identifies discourses (or discursive domains), which constitute different regularised "talk", in the case about microgeneration in the UK. These include discourses relating to: (a) industry sector development; (b) economic development/green growth; (c) energy security and independence; (d) public and community engagement; (e) marketing and consumer protection; (f) fuel poverty; (g) controlling public expenditure; and (h) local authority planning. These may be thought of contending domains which compete for dominance (hegemony) over the "order of discourse" of microgeneration, which may be considered the terrain on which a range of alternative meaning systems vie. The struggle for dominance among discourses occurs through time such that certain ways of talking about microgeneration gain favour whilst others lose prominence, even within a "textual chain". The prevalence of the discourse of fuel poverty within the text of iterations of the UK microgeneration strategy is an example. Thus the 2006 microgeneration strategy mentions fuel poverty 48 times in 55 pages but the 2011 strategy document does not mention fuel poverty at all in 54 pages. "Industry" is becoming more prominent - at least on the basis of a simple count of mentions - appearing 51 times in the 2006 strategy but 75 times in the 2011 document $[49,50]$.

The analysis of discursive practice should address the consumption and production of texts, but is something that tends to be neglected in CDA research. In the present case one can identify the genre of consultations on microgeneration, which fed into the production of the microgeneration strategy documents and are repeatedly cited as informing them within the strategy documents. These consultations involved industrialists, NGOs and policy practitioners but not the general public. A report on the consultation (entitled the "Energy Generating Democracy") makes it clear that "those with the greatest knowledge and expertise in the field" were invited by DECC "to contribute to the development of a draft strategy", on which the aforementioned stakeholders were then consulted [54]. The interviews undertaken for the author's earlier research on microgeneration represent another genre, one in which the language use of those interviewed is framed by the questions posed by the interviewer and the degree of openness of the interview schedule. Scrutiny of styles of discursive practice shows how government identifies passive "consumers" who will consume low carbon energy products but also active consumers if not "citizens" (to which NGOs are more likely to refer). Essentially, there is a difference between representations which privilege transition as driven by development and support for (selected) technologies and markets, and those which conceive of it as requiring fundamental transformation of how and where citizens live and work, and of their relation to energy and food production, calling into question their self-identity and self-governance. The analysis of discursive practice identifies discursive coalitions, clusters and affinities [36]. In the present case discourse coalitions sharing similar "constructs" might be exemplified in relation to the activism of citizens and communities or to microgeneration as an economic opportunity. The prima facie evidence shows that in the UK politicians and industrialists, on one hand, and NGOs and energy advisers on the 
other appear to form distinct discourse clusters in which microgeneration is valued differently. Such difference illustrates possible islands of discourse affinity.

\subsection{Social Practice}

The protagonists' relation to prior history and contemporary conditions and relationships, direct and indirect, frames the possibilities for action and thought open to them. To analyse these conditions as implicated in text and discursive practices is, effectively, to mount a critique of society. The approach proposed here suggests that analysis of social practice may enable the interrogation of factors, which prefigure actors' dispositions, and interventions, which if regularised enact institutions. The hegemony of neo-liberalism in UK is an issue for analysis. In particular, this examines the implications for institutional innovation and governance of sustainability of an emphasis on individualism, the primacy of market relations and consumer choice over collectivism, non-market relations and citizens as active shapers of a "better" society. Another strand in the analysis concerns the implications for governance institutions of policy makers' preoccupation with economic growth, a focus that has tightened with the recent recessions and the financial crisis, and with the "need" to grow the low carbon economy, whilst "keeping the lights on" and energy bills low. The analysis of political and economic structures and the framing of possibilities for governance interrogate the notion that the market rather than the state will generate the investment required in infrastructure and that government should focus on creating the "right" framework for enabling this. In relation to microgeneration such analysis addresses the enactment and reproduction of prevailing social conditions and relations in texts such as acts of parliaments and measures, which speak to the economic opportunities and problems of climate change and energy markets rather more than they do to citizen influence or participation in governance processes. Examination of norm- and culture/cognitive-related discourse institutions, which reproduce or alter social relations, attends to the responsibilities and scope of activity of energy suppliers, for example, to identify innovations in their business models, and the extent to which they become institutionalised. They also relate to the extent which citizens/consumers see themselves legitimately as energy generators either as individuals or within community energy initiatives.

\section{Concluding Discussion}

The paper has been concerned with how better to understand the governance of the transition to sustainability. In fact, this "transition" is yet to occur as there is much evidence of the persistence of variously unsustainable practices. These may be juxtaposed with actions, norms and beliefs, which have the potential to institutionalise sustainability at different scales. The paper has shown that neo-institutional analysis may allow inspection of stability and change (perhaps of changing), analysis which will be deepened to the extent that critical discourse analysis (CDA) is adopted.

The paper makes a contribution to knowledge by proposing a discourse-institutional approach, in which the reproduction of existing institutional rules and the creation, diffusion and embedding of new ones is constituted in language and non-discursive phenomena. The paper identified particular contributions to institutional theory and discourse analysis, which inform the proposed approach. Specifically, work on neo-institutionalism in sociology was invoked, which was orientated towards analysis of a wide range of organisational field actors, rules and rule mechanisms, carriers and 
processes implicated in institutional persistence and change, and for which social practice is not taken as a given but requires scrutiny. At the same time CDA offers a way to investigate manifold relations among analytically distinct yet empirically suffused phenomena (text, discursive practice, and social practice), which partly constitute prevailing or new institutions. CDA also has the benefit of drawing attention to the fact and means by which domination of a field of activity occurs, in this case relating to the dominance or marginalisation of certain actors related to or perspectives of microgeneration.

Some questions arise regarding the critical discourse analysis element of the framework, which the paper can now reflect upon. First, there is the matter of the extent to which language is constitutive of institutions. In his conception of critical discourse analysis, Fairclough leaves room for materiality to shape (and presumably to be shaped by) societal phenomena. But it is unclear how this ought to be analysed in a discursive approach. Here, it is suggested that invoking an approach such as neo-institutional analysis can effect scrutiny of non-discursive elements of institutions. This should include examination of the regularity of material (e.g., financial) allocations to particular types of initiatives, technologies or organisations. Secondly, in terms of operationalising textual analysis there is a question mark regarding the selection of research topic and cases. The proposed framework was illustrated with a case study of microgeneration in the UK since 2003. In line with the methodology underpinning CDA the topic and case were selected for their salience as a problem for society, and for the potential to highlight issues of concern to the researcher and others. These centre on the apparent difficulties involved in institutionalising environmentally sustainable practices through UK society, but also connected with the de-institutionalisation of prevailing behaviour and values and the partial or non-institutionalisation of innovative "rules of the game". Fundamentally, they also concern the sources of persuasion and dominance of governance inherent in text, discursive practice and social structures, which marginalise certain actors and perspectives from the environmental sustainability "field" of which microgeneration is a part. This is to the detriment of the democracy of governance and harmful to the capacity of protagonists and would be actors to fulfil their potential as political and pro-environmental agents. The case study demonstrates the primacy of economic arguments and considerations in texts and wider social structures, which reduces the space for environmental interests, renewable energy technologies and citizens to contribute to pro-environment institutional change.

Thirdly, there is a methodological issue connected with universalism. Are analytic frameworks to be devised and revised for each particular instance to be examined, as Fairclough suggests in his approach to CDA? Or, should researchers aim for more generic frameworks, which may be applied in a more or less standard form across cases? There is a tension between the aspiration of institutional theorists to conceptual and methodological tightness and the argument of certain proponents of critical discourse analysis [55], which emphasises contingency and flexibility of method. The argument herefollowing Phillips and Jorgensen-is for a systematic yet context-sensitive approach [56]. The approach suggested here draws attention to certain common features that analysts should examine in particular cases: the definition of and the actors in an organisational field; the three institutional pillars; the mechanisms which give strength to institutional rules; the three processes and the three carriers by which institutions may become embedded, diffuse and legitimated; and the texts, discursive and social practice, analysis of which show the role that language plays in producing and reproducing institutions. The proposed approach is offered as a "point of entry" for a more systematic analysis of discourseinstitutions, rather than a rigid template or research "protocol" [55]. The precise operationalization of 
the framework, including which aspects are emphasised and whether others are brought into the analysis will depend on the specifics of the research question and setting under investigation.

A fourth point concerns the selection of texts and the depth of analysis of language. To be true to the detail of some versions of discourse analysis one could have included here more forensic and sophisticated linguistic analysis, taking in the analysis of semantics, collocation and so on. But (how) would such analysis be accommodated within a transdisciplinary approach, while being mindful of institutionalised practices of academic writing, publication and presentation, which constrain lengthy (or overly dense) exposition, and the danger of superficial colonisation of fields new to researchers? The answer to this question lies somewhere between methodological preference and being pragmatic about the research to be conducted. The approach to CDA informing the paper is less deeply "linguistic" and more "political" than other approaches to discourse analysis, such as social linguistic analysis. The position taken here considers that it is justified to focus on language use relevant to social and political inequality or change at a broad level, rather than to engage in the formal scrutiny of the micro-world of participants' turn-taking and meaning making found in social linguistic analysis. Bearing in mind the labour intensive nature of close and detailed scrutiny of language, and the resources available to most research projects, it is unlikely that many texts can manageably be handled in any one investigation. However, it is certainly possible - and desirable - to avoid reliance on the one or two texts on which many CDA analyses are based. The approach advocated here is for selection of texts justified on the basis of their relevance to the research problem and question, which should be closely defined, and in such a way as to avoid accusations of cherry picking to produce as persuasive and insightful an account as possible. It is here that institutional analysis and non-discursive analysis of documentary and other material pertaining to the case study under scrutiny may complementarily fill in the historical and social context of the case study and how these have been produced from the interactions and actions of protagonists. Finally, it is one thing to diagnose some problems for sustainability governance on the basis of discourse-institutional analysis but it is another to explicate how or even whether academic researchers should move from analysis to prescription of policy and other measures that might improve matters. One suggestion for policy that appears justified by the work of the paper is that policy-makers need to be mindful of the range of factors which create institutions or impede institutional change in ostensibly preferred directions. These factors include language-based discursive, as well non-discursive, elements.

\section{Acknowledgments}

The author wishes to thank the anonymous reviewers for comments on an early draft of this paper. All views expressed in the paper, and any omissions or errors therein, are those of the author.

\section{Conflicts of Interest}

The author declares no conflict of interest. 


\section{References}

1. Shove, E.; Walker, G. Governing transitions in the sustainability of everyday life. Res. Policy 2010, 39, 471-476.

2. Finkelstein, L. What is global governance? Glob. Gov. 1995, 1, 367-372.

3. Mol, A.P.J. Ecological modernisation and institutional reflexivity: Environmental reform in the late modern age. Environ. Polit. 1996, 5, 302-323.

4. Edquist, C.; Johnson, B. Institutions and Organisations in Systems of Innovation. In Systems of Innovation: Technologies, Institutions and Organizations; Edquist, C., Ed.; Routledge: London, UK, 1997; pp. 41-63.

5. Nelson, R.R.; Winter, S.G. An Evolutionary Theory of Economic Change; Harvard University Press: Cambridge, MA, USA, 1982.

6. North, D.C. Institutional Change and Economic Performance; Cambridge University Press: Cambridge, UK, 1990.

7. Johnson, B. Institutional Learning. In National Systems of Innovation: Towards a Theory of Innovation and Interactive Learning; Lundvall, B.A., Ed.; Pinter: London, UK, 1992; pp. 23-45.

8. Fairclough, N. Analyzing Discourse: Textual Analysis for Social Research; Routledge: London, UK, 2003.

9. Scott, W.R. Institutions and Organizations: Ideas and Interests; 3rd ed.; Sage: Thousand Oaks, CA, USA, 2008.

10. Scott, W.R. Approaching adulthood: the maturing of institutional theory. Theory Soc. 2008, 37, 427-442.

11. Selznick, P. Leadership in Administration; Harper and Row: New York, NY, USA, 1957.

12. Tolbert, P.S.; Zucker, L.G. Institutional sources of change in the formal structure of organizations: The diffusion of civil service reforms 1880-1935. Adm. Sci. Q. 1983, 23, 22-39.

13. DiMaggio, P.J.; Powell, W.W. The iron cage revisited: Institutional isomorphism and collective rationality in organizational fields. Am. Sociol. Rev. 1983, 48, 147-160.

14. Meyer, J.W.; Rowan, B. Institutionalized organizations: Formal structure as myth and ceremony. Am. J. Sociol. 1977, 83, 340-363.

15. Friedland, R.; Alford, R. Bringing Society Back in: Symbols, Practices and Institutional Contradictions. In The New Institutionalism in Organizational Analysis; Powell, W.W., DiMaggio, P.J., Eds.; University of Chicago Press: Chicago, IL, USA, 1991; pp. 232-263.

16. Jepperson, R.L. Institutions, Institutional Effects, and Institutionalization. In The New Institutionalism in Organizational Analysis; Powell, W.W., DiMaggio, P.J., Eds.; University of Chicago Press: Chicago, IL, USA, 1991; pp. 143-163.

17. Scott, W.R. Institutional carriers: Reviewing modes of transporting ideas over time and space and considering their consequences. Ind. Corp. Chang. 2003, 12, 879-894.

18. Geels, F.W. From sectoral systems of innovation to socio-technical systems: Insights about dynamics and change from sociology and institutional theory. Res. Policy 2004, 33, 897-920.

19. Genus, A. Changing the rules? Institutional innovation and the diffusion of micro-generation. Technol. Anal. Strateg. Manag. 2012, 24, 711-727. 
20. Wolsink, M. The research agenda on social acceptance of distributed generation in smart grids: Renewable as common pool resources. Renew. Sustain. Energy Rev. 2012, 16, 822-835.

21. German, L.A.; Schoneveld, G. Biofuel Investments in sub-Saharan Africa: A review of the early legal and institutional framework in Zambia. Rev. Policy Res. 2012, 24, 467-491.

22. Reddy, S.; Painuly, J.P. Diffusion of renewable energy technologies-Barriers and stakeholders' perspectives. Renew. Energy 2004, 29, 1431-1447.

23. Söderberg, C. Institutional conditions for multi-sector environmental policy integration in Swedish bioenergy policy. Environ. Polit. 2011, 20, 528-546.

24. Szarka, J. Wind power, policy learning and paradigm change. Energy Policy. 2006, 34, 3041-3048.

25. Dosi, G. Technological paradigms and technological trajectories. Res. Policy. 1982, 1, 147-162.

26. Rip, A.; Kemp, R. Technological Change. In Human Choice and Climate Change, volume 2: Resources and Technology; Rayner, S., Malone, E.J., Eds.; Battelle Press: Columbus, IN, USA, 1998; pp. 327-399.

27. Dolata, U. Technological innovations and sectoral change: Transformative capacity, adaptability, patterns of change: An analytical framework. Res. Policy 2009, 38, 1066-1076.

28. Streeck, W.; Thelen, K. Introduction: Institutional change in Advanced Political Economies. In Beyond Continuity. Institutional Change in Advanced Political Economies; Streeck, W., Thelen, K., Eds.; Oxford University Press: Oxford, UK, 2005; pp. 3-39.

29. Verbong, G.; Geels, F. The ongoing energy transition: Lessons from a socio-technical, multi-level analysis of the Dutch electricity (1960-2004). Energy Policy. 2007, 32, 1025-37.

30. Geels, F.W.; Kemp, R. Dynamics in socio-technical systems: A typology of change process and contrasting case studies. Tech. Soc. 2007, 29, 441-455.

31. Bergek, A.; Hekkert, M.; Jacobsson, S. Functions in Innovation Systems: A Framework for Analysing Energy System Dynamics and Identifying Goals for System-Building Activities by Entrepreneurs and Policy-Makers. In Innovation for a Low Carbon Economy: Economic, Institutional and Management Approaches; Foxon, T., Kohler, J., Oughton, C., Eds.; Edward Elgar: Cheltenham, UK, 2008; pp. 79-111.

32. Bergek, A.; Jacobsson, S.; Carlsson, B.; Lindmark, S.; Rickne, A. Analyzing the functional dynamics of technological innovation systems: A scheme of analysis. Res. Policy. 2008, 37, 407-429.

33. Woolthuis, R.K.; Hooimeijer, F.; Bossink, B.; Mulder, G.; Brouwer, J. Institutional entrepreneurship in sustainable urban development: Dutch successes as inspiration for transformation. J. Clean. Prod. 2013, 50, 91-100.

34. Mazza, L.; Rydin, Y. Urban sustainability: discourses, networks and policy tools. Progr. Plann. 1997, 41, 1-74.

35. Hajer, M. The Politics of Environmental Discourse: Ecological Modernization and the Policy Process; Oxford University Press: Oxford, UK, 1995.

36. Hajer, M. Discourse Coalitions and the Institutionalization of Practice: The Case of Acid Rain in Britain. In The Argumentative Turn in Policy Analysis and Planning; Fischer, F., Forrester, J., Eds.; Duke University Press: Durham, UK, 1993; pp. 43-76.

37. Fischer, F. Policy Discourse and the Politics of Washington Think Tanks. In The Argumentative Turn in Policy Analysis and Planning; Fischer, F., Forrester, J., Eds.; Duke University Press: Durham, UK, 1993; pp. 21-42. 
38. Smith, A.; Kern, F. The transitions storyline in Dutch environmental policy. Environ. Policy 2009, 18, 78-98.

39. Rydin, Y. Conflict, Consensus and Rationality and Environmental Planning; Oxford University Press: Oxford, UK, 2003.

40. March, J.; Olsen, J. Rediscovering Institutions: The Organizational Basis of Politics; Free Press: New York, NY, USA, 1989.

41. Ostrom, E.; Gardner, R.; Walker, J. Rules, Games and Common-Pool Resources; University of Michigan Press: Ann Arbor, MI, USA, 1994.

42. Rydin, Y. Can we talk ourselves into sustainability? The role of discourse in the environmental policy process. Environ. Values 1999, 8, 467-484.

43. Palmer, J. Stopping the unstoppable? A discursive-institutionalist analysis of renewable transport fuel policy. Environ. Plan. C Gov. Policy 2010, 28, 992-1010.

44. Fairclough, N. Language and Power; Longman: London, UK, 2001.

45. Fairclough, N. Discourse analysis in organization studies: The case for critical realism. Org. Stud. 2005, 26, 915-39.

46. Department of Energy and Climate Change (DECC). UK Low Carbon Transition Plan, 2009: National Strategy for Climate and Energy; TSO: Norwich, UK, 2009.

47. Department of Environment. Food and Rural Affairs (DEFRA). A Framework for Pro-Environmental Behaviours; DEFRA: London, UK, 2008.

48. Department of Energy and Climate Change. The UK Renewable Energy Strategy. Cm 7686; TSO: Norwich, UK, 2009.

49. Department of Trade and Industry. Our Energy Challenge: Power from the People. Available online: http://webarchive.nationalarchives.gov.uk/20080205151941/http:/www.berr.gov.uk/files/ file27575.pdf (accessed 19 November 2013).

50. Department of Energy and Climate Change. Microgeneration Strategy. Available online: https://www.gov.uk/government/uploads/system/uploads/attachment_data/file/48114/2015-microgenerationstrategy.pdf (accessed on 19 November 2013).

51. Department of Energy and Climate Change. Consultation on a Microgeneration Strategy. Available online: https://www.gov.uk/government/uploads/system/uploads/attachment_data/file/ 42711/1077-consultation-on-a-microgeneration-strategy.pdf (accessed on 19 November 2013).

52. Bergman, N.; Jardine, C. Power from the People: Domestic Microgeneration and the Low Carbon Buildings Programme; Environmental Change Institute: Oxford, UK, 2009.

53. Feed-in Tariff, Annual Report 2011-2012. Available online: https://www.ofgem.gov.uk/ publications-and-updates/feed-tariff-fit-annual-report-2011-2012 (accessed on 19 November 2013).

54. Energy Efficiency Partnership for Homes. The Energy Generating Democracy: DECC Microgeneration Strategy Consultation Final Report. Available online: https://www.gov.uk/ government/uploads/system/uploads/attachment_data/file/42714/668-energy-generating-democracymicrogen.pdf (accessed on 19 November 2013).

55. Chouliaraki, L.; Fairclough, N. Critical discourse analysis in organizational studies: Towards an integrationist methodology. J. Manag. Stud. 2010, 47, 1213-1218. 
56. Phillips, L.; Jorgensen, M.W. Discourse Analysis as Theory and Method; Sage: London, UK, 2002.

(C) 2014 by the authors; licensee MDPI, Basel, Switzerland. This article is an open access article distributed under the terms and conditions of the Creative Commons Attribution license (http://creativecommons.org/licenses/by/3.0/). 